\title{
Burden of Anaemia among Women in Jharkhand, India: Does Lifestyle Behaviour Matters?
}

\author{
Keywords: Anaemia; Binary logistic regression; BMl; Life style factor; \\ Jharkhand
}

\begin{abstract}
Anaemia is a major public health problem worldwide, mostly among females of reproductive age in developing countries. In India the prevalence of anaemia among women of age group 15 to 49 years is much higher; particularly in the State of Jharkhand the situation is very worst, almost $69 \%$ women are anaemic. Using data from National Family Health Survey-3, 2005-2006, a nationally representative cross-sectional survey that provided information on anaemia level among 2777 women of Jharkhand state. Prime objective of the paper is to understand the prevalence of anaemia among women and to examine the contribution of lifestyle factors at the women's anaemia level in Jharkhand. Both bi-variate and multivariate techniques have been used. Significant insight of the study is that about $1.3 \%$ of women are severe $(<7.0 \mathrm{~g} / \mathrm{dl}), 16.7 \%$ women are moderate $(7.0-9.9 \mathrm{~g} / \mathrm{dl}), 51.4 \%$ women are mild $(10.0-11.9 \mathrm{~g} / \mathrm{dl})$, in overall about $70.0 \%$ women are having any anaemia $(<12.0 \mathrm{~g} / \mathrm{dl})$. Binary regression analysis shows that place of residence, educational attainment, religion, wealth status, caste, religion, $\mathrm{BMI}(<18.5 .0 \mathrm{~g} / \mathrm{dl}$ ), lifestyle behaviour of the women has a significant impact on the women anaemia status. For policy point of view effective program that targets to reduce the difference existing in socio-economic as well as lifestyle factors that influence the anaemia level of women and also their health, is the greatest prerequisite.
\end{abstract}

\section{Background}

Anaemia is a global public health problem affecting developing and developed countries with major consequences for human health as well as social and economic development. It occurs at all stages of the life cycle but is more prevalent in pregnant women and young children. However, it is ignored in most of the developed and developing countries though it has serious consequences for national development. About 1.62 billion of the world's population are suffering from any anaemia [1]. The burden falls predominantly on Asia and Africa with the complex interplay of dietary factors, infectious disease, genetics and other factors determining anaemia status [2]. Anaemia contributes to almost 1,20,000 maternal death worldwide, in low and middle-income countries, 18 of maternal mortality is attributed to iron deficiency South Asia suffers from some of the highest rates of anaemia worldwide [3], and in India, more than half are anaemic and around one-third of women of reproductive age are underweight [4]. In this region burdened by high maternal mortality, around 13 of maternal deaths are attributable to anaemia. Severe anaemia among women is an important contributor to maternal mortality and morbidity, lowered physical activity and lowered productivity [5-7]. In developing countries, women are more venerable, particularly in respect to their health, health care facilities and having proper food. Anaemia has a potential influence on the

\section{Journal of}

Nutrition and Health

\section{Satish Kumar Chauhan, Suresh Jungari* and Bal Govind Chauhan}

International Institute for Population Sciences, Mumbai, India

\section{*Address for Correspondence}

Suresh Jungari, International Institute for Population Sciences, Govandi Station Road, Deonar, Mumbai, India. Tel: +918451831615; E-mail: sureshjungariiips@gmail.com

Submission: 05 September 2015

Accepted: 31 October, 2015

Published: 03 November, 2015

Copyright: @ 2015 Suresh Jungari et al. This is an open access article distributed under the Creative Commons Attribution License, which permits unrestricted use, distribution, and reproduction in any medium, provided the original work is properly cited.

overall women health and has been a concern for the government of India. The state of Jharkhand is one among the Empowered Action Group (EAG) is known for socioeconomic and demographic backwardness. Many other health indicators for women in Jharkhand remained poor like use of antenatal services, institutional deliveries, etc. The Jharkhand state also has large number of tribes. Tribal population lifestyle behaviour is more influenced by traditional and cultural factors.

The prevalence of various lifestyle indicators such as smoking, alcohol drinking and chewing tobacco has also been increasing. Although, it is presumed that the lifestyle indicators have a close association with prevalence of anaemia [8-10], very less number of studies have attempted to study the same in Indian context. In this context, the present study attempts to understand the association between some selected lifestyle indicators and its association with anaemia level of women in the state of Jharkhand. It has been thought that such an attempt will benefit the policy makers in understanding the current situation and the subsequent need for further program and planning.

\section{Data and Methods}

\section{Data source}

This study utilizes the data extracted from National Family Health Survey (NFHS-3), was conducted in 2005-06 covering twentynine states in India, comprises near about $99 \%$ of India's population. NFHS-3 collected information from nationally representative sample of 109,401 households, with 124,385 women age 15-49 and 74,369 men age 15-54. It provides cross-sectional survey data on women's haemoglobin status, body weight, diet, social, demographic, determinants of India and all its states. A total of 2983 eligible women were interviewed in the Jharkhand and of these 2777 respondents were not pregnant and 206 women were pregnant on the survey date according to their own reporting and were selected for the present study. The main strata used in the sampling procedure were rural and urban areas. The primary sampling units (PSUs) (villages in the rural areas and census enumeration blocks in urban areas) were selected with probability proportional to size sampling and the households 
were selected from within the PSUs. The non-response was not different by background characteristics for women and had not caused any bias in the data.

\section{Methods}

Descriptive statistics and bivariate analysis are carried out to estimate the level and prevalence of anaemia in Jharkhand. Further, bivariate and multivariate analyses are used to understand the socioeconomic and demographic differentials in the prevalence of anaemia level in Jharkhand. Multivariate analysis in terms of Binary logistic regression is done to check the associations of selected socioeconomic and demographic covariates on the prevalence of anaemia in Jharkhand. Binary logistic regression is the most appropriate technique in a situation where the dependent variables are categorical and have two outcomes.

\section{Variables}

\section{Dependent variables}

Anaemia level: Women with any anaemia (mild, moderate, severe) are considered for the study. The level of anaemia among pregnant and non-pregnant women varies, greatly, and for non pregnant women the cut off Haemoglobin level is less than $12 \mathrm{~g} / \mathrm{dl}$ and for pregnant women it is less than $11 \mathrm{~g} / \mathrm{dl}$. For the study point of view we consider only non-pregnant women of reproductive age group. To show the percentage distribution, anaemia variable are divide into three categories; a) Severe (<7.0 g/dl), b) moderate (7.0-9.9 g/dl), c) mild $(10.0-11.9 \mathrm{~g} / \mathrm{dl})$ and for the logistic regression analysis purpose anaemia variable are divide into two categories: Anaemic $(<12 \mathrm{~g} / \mathrm{dl})$ and not anaemic $(>12 \mathrm{~g} / \mathrm{dl})$.

\section{Independent variables}

The study incorporated several independent variables to understand the extent of lifestyle behaviour and its linkage with the level of anaemia in reproductive age women. The socioeconomic and demographic variables are age of women, place of residence, Religion, Caste, wealth index, women education, media exposure, household structure, working status, partner education, children ever born and BMI (recoded as total thin, $<18 \mathrm{~kg} / \mathrm{m}^{2}$; Normal, $18.5-24.9 \mathrm{~kg} . \mathrm{m}^{2}$ and overweight/obese, $>25 \mathrm{~kg} . \mathrm{m}^{2}$ ). Lifestyle behaviour variables are smoking status, consume fruits, pulses and beans, and consume curd or milk, eating non-veg and green leafy vegetable.

\section{Results}

Table 1 showing percentage distribution of women by background characteristics in Jharkhand state, $44 \%$ of women were belongs in 30 and above age group following $22.3 \%$ in age group of $15-19$. Looking at urban-rural differentials $72.2 \%$ women belongs from the rural areas and $27.8 \%$ from urban areas. As far as religion is concern the Hindu religion women are dominating with $71.3 \%$ following 14.7 Muslims and $14 \%$ belongs to other all religions. According to Caste Scheduled Caste (SCs) and Scheduled Tribes (STs) women constitutes 35.8\% whereas other backward Classes (OBC) $46.8 \%$. Nearly half of women belong from the poorest wealth quintile. $58 \%$ of women were not educated and $60 \%$ of women not had any exposure to media. Nearly $70.5 \%$ women do not work. Interestingly $20 \%$ of women given birth to 5 and above children. According to BMI status 43.0 women are thin and only 5.4\% women were obese. Only $11.4 \%$ women were smoking in the women sample at survey time. Only $4.7 \%$ of women consumed fruits daily whereas large number of women $69 \%$ only occasionally consumed fruits. About one third of women daily had pulses and beans in their diet. Consumption of milk and curd is very less among the Jharkhand women, $34 \%$ of women never had milk and curd in their diet and $82 \%$ of women occasionally eat non-vegetarian food and $47 \%$ women have had green leafy vegetables in their diet.

\section{Differential in anaemia level of women by socio economic characteristics}

Table 2 presents the women age 25-29 years are more severely anaemic with compared to other age groups of women. The women aged 30 and above years are mildly anaemic (51.0). The rural women are more anaemic whereas the women in the urban area less anaemic. In Jharkhand, a great diversity is found in prevalence of anaemia among various caste and class. A difference of approximate 14\% in between scheduled caste/tribes and others caste (except other backward caste) in moderately anaemic category and about $7 \%$ in mild anaemic can be seen in which the high women suffering anaemia belongs to scheduled caste/tribes. Education leads to awareness, and the effect of education is reflected in the statistics of women suffering from anaemia. Women with no education are more anaemic than the women who are educated. The higher percentage of women lies in mild anaemic where poorest women are (52.0), poor (53.0), middle (45.0), richer (44.0) and richest (46.0). Similarly, the more severely anaemic women are found among poorest. Therefore, it can be seen that as the economic status escalates the degree of anaemic severity reduces. Women form nuclear family are more anaemic than its counterparts, about $51 \%$ of women are mild anaemic whereas about $49 \%$ women are mild anaemic in no-nuclear families.

\section{Life style behaviour factors and anaemia level of women}

According to lifestyle behaviour factors it is showing that, high percentages of women suffering from moderate and mild anaemia are underweight whereas the normal weight women and overweight are less anaemic. Those women who smoke \& chew tobacco contribute a high percentage in severely anaemic (1.4) than those who are nonsmokers and do not chew tobacco. The similar trend can be seen in the moderate \& mild anaemic women. Those women, who are currently working, are more suffering from all type of anaemia than the women who are not working. Women daily consuming milk or curd, fruits, eating non-veg once in a week are less anaemic than its counterparts.

\section{Logistic regression results}

The odd ratios and $95 \mathrm{CI}$ of the logistic regressions are presented in Table 3. Three models, we applied to see the determinant of the anaemia level among women. In the first model socio-economic and demographic factor, in second model life style factor and in the third model all variables we have included for the analysis. In the Model 1 , women belonging 20 and above age groups had significantly low odds of being anaemic compared with women belonging to 15-19 years age group category. Women age 30 and above years are 13\% less likely to being anaemic $(\mathrm{OR}=831, \mathrm{Cl}=0.572,1.207)$. Women belonging to Rural area and belongs to other religion are more likely to anaemic ( $\mathrm{OR}=1.031, \mathrm{Cl}=766,1.387$ and $\mathrm{OR}=1.279, \mathrm{Cl}=895$, 1.827 respectively) than women belongs to urban area and Hindu 
Citation: Satish Kumar C, Suresh J, Chauhan BG. Burden of Anaemia among Women in Jharkhand, India: Does Lifestyle Behaviour Matters? J Nutri Health. 2015;1(2): 9.

ISSN: 2469-4185

Table 1: Percentage distribution of women by background characteristics in Jharkhand, 2005-06

Percentage distribution of Non pregnant women by background characteristics in Jharkhand, 2005-06

Women's Age

15-19 year

20-24 year

25-29 year

30 and above

\section{Place of Residence}

Urban

Rural

\section{Religion}

Hindu

Muslim

Other

Caste

SC/ST

OBC

OTHERS

Wealth index

Poorest

Poorer

Middle

Richer

Riches

Women Education level

No education

Primary

Secondary

Higher

Partner Education

No education

Primary

Secondary

Higher

Children ever born

No Child

1-2 Child

3-4 Child

5 and above

Media exposure

No exposure

Any exposure

Household Structure

Nuclear

Non-Nuclear

\begin{tabular}{|c|c|}
\hline $\mathrm{n}$ & $\%$ \\
\hline 615 & 22.3 \\
\hline 517 & 18.6 \\
\hline 428 & 15.3 \\
\hline 1217 & 43.9 \\
\hline 1106 & 27.8 \\
\hline 1671 & 72.2 \\
\hline 2009 & 71.3 \\
\hline 424 & 14.7 \\
\hline 344 & 14.0 \\
\hline 906 & 35.8 \\
\hline 1283 & 46.8 \\
\hline 588 & 17.3 \\
\hline 1080 & 45.9 \\
\hline 381 & 15.1 \\
\hline 331 & 11.7 \\
\hline 444 & 13.3 \\
\hline 541 & 14.0 \\
\hline 1454 & 58.0 \\
\hline 276 & 9.9 \\
\hline 696 & 22.4 \\
\hline 348 & 9.6 \\
\hline 748 & 38.1 \\
\hline 269 & 13.0 \\
\hline 888 & 39.3 \\
\hline 266 & 9.7 \\
\hline 787 & 27.4 \\
\hline 747 & 26.3 \\
\hline 720 & 26.3 \\
\hline 523 & 20.1 \\
\hline 1452 & 59.0 \\
\hline 1325 & 41.0 \\
\hline 1248 & 44.5 \\
\hline 1529 & 55.5 \\
\hline
\end{tabular}


Citation: Satish Kumar C, Suresh J, Chauhan BG. Burden of Anaemia among Women in Jharkhand, India: Does Lifestyle Behaviour Matters? J Nutri Health. 2015;1(2): 9.

ISSN: $2469-4185$

\begin{tabular}{|c|c|c|}
\hline Woking Status & & \\
\hline No & 2014 & 70.5 \\
\hline Yes & 759 & 29.5 \\
\hline \multicolumn{3}{|l|}{ BMI of the Women } \\
\hline Total thin $\left(<18.5 \mathrm{~kg} / \mathrm{m}^{2}\right)$ & 1079 & 43.0 \\
\hline Normal(18.5- $\left.24.9 \mathrm{~kg} / \mathrm{m}^{2}\right)$ & 1375 & 51.6 \\
\hline Overweight \& obese $\left(\geq 25 \mathrm{~kg} / \mathrm{m}^{2}\right)$ & 186 & 5.4 \\
\hline \multicolumn{3}{|l|}{ Smoking Status } \\
\hline No & 2486 & 88.6 \\
\hline Yes & 291 & 11.4 \\
\hline \multicolumn{3}{|l|}{ Consume Fruits } \\
\hline Never & 145 & 6.0 \\
\hline Weekly & 623 & 20.2 \\
\hline Occasionally & 1840 & 69.1 \\
\hline \multicolumn{3}{|l|}{ Pluses and beans } \\
\hline Daily & 998 & 32.1 \\
\hline Weekly & 1181 & 43.5 \\
\hline Occasionally & 598 & 24.3 \\
\hline \multicolumn{3}{|l|}{ Consume curd or Milk } \\
\hline Never & 854 & 34.4 \\
\hline Daily & 512 & 15.4 \\
\hline Weekly & 233 & 7.3 \\
\hline Never & 258 & 8.4 \\
\hline Occasionally & 300 & 9.7 \\
\hline Weekly & 2219 & 81.9 \\
\hline \multicolumn{3}{|l|}{ Green leafy vegetable } \\
\hline Daily & 1374 & 46.9 \\
\hline Weekly & 1048 & 38.7 \\
\hline Sometime & 355 & 14.4 \\
\hline Total & 2777 & 100 \\
\hline
\end{tabular}

Note: $\mathrm{n}$ indicates the un-weighted sample and percentage distribution is weighted. Number is not equal due to missing cases.

women. Women education is negatively associated with the anaemia level of women. As the education level of women increases the odds of having anaemia is decreasing. Women belongs to secondary and higher education category are less likely to anaemic than women belongs to no educated category $(\mathrm{OR}=0.901, \mathrm{C} \mathrm{l}=0.666,1.217$ and $\mathrm{OR}=0.787, \mathrm{C} \mathrm{l}=0.476,1.296$ respectively). Working women are also significantly more risk of having anaemia than non-working women ( $\mathrm{OR}=1.295,1.040-1.613)$. It is also observed that women with more number of children are significantly more likely to have anaemia than women with no children. As the numbers of children are increasing the odds of having anaemia is also increasing. Women with $1-2$ children are $51 \%$ more likely $(\mathrm{OR}=1.513, \mathrm{Cl}=1.107,2.068)$, women with 3-4 children are 55\% more likely $(\mathrm{OR}=1.550, \mathrm{Cl}=1.089$, 2.206) and women having 5 and more children are 57\% more likely
$(\mathrm{OR}=1.576, \mathrm{Cl}=1.070,2.323)$ to have anaemia than women have no children.

In the model 2, which assessing the association between life style factors and anaemia level of the women are showing the odds of anaemia is less among women with normal BMI (OR $=0.955$, C $l=0.809,1.127)$ and in contrast, significantly less in overweight/obese category $(\mathrm{OR}=0.629, \mathrm{Cl}=0.442,0.896)$ compare to thin women. It was observed that the women who reported smoke or consume tobacco were more likely to be anaemic than those who did not smoke or consume tobacco $(\mathrm{OR}=1.353 \mathrm{C} \mathrm{l}=1.023,1.790)$. It was observed that woman who consume fruits, either daily or weekly or occasional, were significantly less likely to be anaemic than their counterparts who never eat fruits $(\mathrm{OR}=0.663, \mathrm{Cl}=0.383,1.148$ 
Citation: Satish Kumar C, Suresh J, Chauhan BG. Burden of Anaemia among Women in Jharkhand, India: Does Lifestyle Behaviour Matters? J Nutri Health. 2015;1(2): 9.

ISSN: $2469-4185$

Table 2: Prevalence of anaemia among women (15-49 years) by socio economic and different Life style background characteristics in Jharkhand, $2005-06$.

\begin{tabular}{|c|c|c|c|c|c|}
\hline Covariates & Severe & Moderate & Mild & Anaemia & $\mathbf{n}$ \\
\hline \multicolumn{6}{|c|}{ Socio-economic and demographic variables } \\
\hline \multicolumn{6}{|l|}{ Women's Age } \\
\hline 15-19 year & 0.8 & 17.8 & 48.6 & 67.2 & 621 \\
\hline 20-24 year & 1.6 & 20 & 47.7 & 69.3 & 549 \\
\hline 25-29 year & 1.8 & 20.5 & 48.2 & 70.4 & 448 \\
\hline 30 and above & 1.3 & 17.6 & 51.5 & 70.3 & 1159 \\
\hline \multicolumn{6}{|c|}{ Place of Residence } \\
\hline Urban & 0.8 & 12 & 45.8 & 58.6 & 1050 \\
\hline Rural & 1.5 & 20.9 & 50.9 & 73.3 & 1727 \\
\hline \multicolumn{6}{|l|}{ Religion } \\
\hline Muslim & 0.8 & 15.4 & 45.6 & 61.8 & 409 \\
\hline Other & 1.2 & 26.1 & 56.6 & 83.9 & 346 \\
\hline \multicolumn{6}{|l|}{ Caste } \\
\hline SC/ST & 1.9 & 25.8 & 53.3 & 81 & 919 \\
\hline OBC & 1 & 15.4 & 47.8 & 64.2 & 1298 \\
\hline Other & 0.8 & 11.9 & 46.6 & 59.3 & 560 \\
\hline \multicolumn{6}{|l|}{ Wealth Index } \\
\hline Poorest & 1.6 & 23.2 & 51.8 & 76.6 & 1130 \\
\hline Poorer & 1.4 & 16.6 & 53.4 & 71.4 & 391 \\
\hline Richest & 0.4 & 8.6 & 46 & 55 & 506 \\
\hline \multicolumn{6}{|c|}{ Women's Education } \\
\hline No education & 1.8 & 20.8 & 50.9 & 73.5 & 1483 \\
\hline Primary & 0 & 20.8 & 48.5 & 69.3 & 284 \\
\hline Secondary & 0.9 & 15.5 & 47.2 & 63.6 & 684 \\
\hline Higher & 0.8 & 8.8 & 47.7 & 57.4 & 323 \\
\hline \multicolumn{6}{|c|}{ Media Exposure } \\
\hline No exposure & 1.5 & 21.2 & 51.7 & 74.4 & 1503 \\
\hline Any exposure & 1 & 14.5 & 46.2 & 61.8 & 1274 \\
\hline \multicolumn{6}{|c|}{ Household Structure } \\
\hline Nuclear & 1.3 & 19.6 & 50.7 & 71.7 & 1215 \\
\hline Non-Nuclear & 1.3 & 17.8 & 48.7 & 67.8 & 1562 \\
\hline \multicolumn{6}{|c|}{ Women Work Status } \\
\hline Not working & 1.2 & 15.8 & 45.5 & 66.8 & 2017 \\
\hline Working & 1.4 & 20.6 & 52.6 & 76.4 & 755 \\
\hline \multicolumn{6}{|c|}{ Partner Education } \\
\hline No education & 1.5 & 22 & 50.8 & 74.3 & 777 \\
\hline Primary & 2.2 & 19.4 & 48 & 69.6 & 283 \\
\hline
\end{tabular}


Citation: Satish Kumar C, Suresh J, Chauhan BG. Burden of Anaemia among Women in Jharkhand, India: Does Lifestyle Behaviour Matters? J Nutri Health. 2015;1(2): 9.

ISSN: 2469-4185

\begin{tabular}{|c|c|c|c|c|c|}
\hline Secondary & 0.9 & 18.6 & 48.6 & 68.2 & 898 \\
\hline Higher & 0.9 & 12.3 & 47.4 & 60.5 & 262 \\
\hline \multicolumn{6}{|l|}{ Children ever born } \\
\hline No Child & 1.2 & 14.9 & 48.6 & 64.7 & 781 \\
\hline 1-2 Child & 1.3 & 20.8 & 47.3 & 69.5 & 771 \\
\hline 3-4 Child & 1.2 & 20.4 & 49.7 & 71.2 & 713 \\
\hline 5 and above & 1.5 & 18 & 54.1 & 73.6 & 512 \\
\hline \multicolumn{6}{|l|}{ Life style variables } \\
\hline \multicolumn{6}{|l|}{ BMI of Women } \\
\hline Total thin $\left(<18.5 \mathrm{~kg} / \mathrm{m}^{2}\right)$ & 1.1 & 19.3 & 51.3 & 71.7 & 1123 \\
\hline Normal(18.5- 24.9 kg/m²) & 1.6 & 18.8 & 48.9 & 69.2 & 1464 \\
\hline \multicolumn{6}{|l|}{ Smoke/Consume Tobacco } \\
\hline No & 1.3 & 17.9 & 49.1 & 31.7 & 2488 \\
\hline Yes & 1.4 & 24.1 & 53 & 21.5 & 289 \\
\hline \multicolumn{6}{|l|}{ Consume Fruits } \\
\hline Never & 2.1 & 21.1 & 55.3 & 78.5 & 149 \\
\hline Daily & 1.1 & 12.7 & 41.5 & 55.3 & 160 \\
\hline Weekly & 0.5 & 15.4 & 47.4 & 63.4 & 621 \\
\hline Occasionally & 1.5 & 19.7 & 50.2 & 71.4 & 1864 \\
\hline \multicolumn{6}{|l|}{ Pluses and beans } \\
\hline Sometime & 1.9 & 21.2 & 53.7 & 76.8 & 600 \\
\hline \multicolumn{6}{|l|}{ Consumed Milk or Curd } \\
\hline Never & 1.7 & 24.7 & 51.8 & 21.7 & 860 \\
\hline Daily & 0.9 & 13.5 & 47.1 & 38.5 & 496 \\
\hline Weekly & 1.4 & 10.6 & 44.8 & 43.2 & 230 \\
\hline Occasionally & 1.1 & 16.8 & 49.4 & 32.7 & 1191 \\
\hline \multicolumn{6}{|l|}{ Eating non-Veg. } \\
\hline Never & 0 & 12.4 & 50.4 & 62.7 & 258 \\
\hline Occasionally & 1.5 & 19.6 & 50 & 71.1 & 295 \\
\hline Weekly & 0.7 & 14.9 & 45.5 & 61.1 & 2224 \\
\hline \multicolumn{6}{|l|}{ Green leafy vegetable } \\
\hline Daily & 1.4 & 17 & 49.4 & 67.8 & 1350 \\
\hline Weekly & 1 & 19.3 & 49.1 & 69.4 & 1069 \\
\hline Sometime & 1.6 & 21.4 & 51.9 & 74.9 & 358 \\
\hline Total & 1.3 & 18.6 & 49.6 & 69.5 & 2777 \\
\hline
\end{tabular}

Note: Anemia category included the all the severely, Moderate and mild anemic women.

Severely Anemia (<7.0 g/dl), Moderate Anemic (7.0-9.9 g/dl), Mild Anemic (10.0-11.9 g/dl).

$\mathrm{n}$ - refer to un-weighted cases and $\mathrm{n}$ not equal due to missing cases.

for women who eat daily fruits and OR $0.778, \mathrm{C} l=0.507,1.194$ for women who eat fruits weekly). Consumption of milk or curd is also significantly associated with anaemia level of women; however the odds is not much difference in the daily, weekly and occasionally 
Citation: Satish Kumar C, Suresh J, Chauhan BG. Burden of Anaemia among Women in Jharkhand, India: Does Lifestyle Behaviour Matters? J Nutri Health. 2015;1(2): 9.

ISSN: 2469-4185

Table 3: Binary Logistic Regression Models Showing Odds Ratio (OR) and Confidence Interval (Cl) for prevalence of anaemia among Women (Aged 15-49 Years), Jharkhand, 2005-06

\begin{tabular}{|c|c|c|c|}
\hline Covariates & Model 1 & Model 2 & Model 3 \\
\hline \multicolumn{4}{|l|}{ Women's Age } \\
\hline \multicolumn{4}{|l|}{$15-19$ year® } \\
\hline 20-24 year & $.910(.641-1.293)$ & & $.907(.637-1.292)$ \\
\hline 25-29 year & $.872(.590-1.289)$ & & $.854(.576-1.267)$ \\
\hline 30 and above years & $.831(.572-1.207)$ & & $.840(.575-1.228)$ \\
\hline \multicolumn{4}{|l|}{ Place of Residence } \\
\hline \multicolumn{4}{|l|}{ Urban® } \\
\hline Rural & $1.031(.766-1.387)$ & & $.986(.730-1.332)$ \\
\hline \multicolumn{4}{|l|}{ Religion } \\
\hline \multicolumn{4}{|l|}{ Hindu® } \\
\hline Muslim & $.874(.673-1.135)$ & & $.834(.636-1.093)$ \\
\hline \multicolumn{4}{|l|}{ Caste } \\
\hline \multicolumn{4}{|l|}{$\mathrm{SC} / \mathrm{ST} \circledast$} \\
\hline OBC & $.544^{* * *}(.427-.693)$ & & $.563^{\star * \star}(.438-.723)$ \\
\hline Other & $.631^{* \star *}(.455-.875)$ & & $.660^{\star * *}(.473-.921)$ \\
\hline \multicolumn{4}{|l|}{ Wealth Index } \\
\hline \multicolumn{4}{|l|}{ Poorest $\circledast$} \\
\hline Poorer & $.930(.704-1.229)$ & & $.965^{*}(.727-1.282)$ \\
\hline Middle & $.677^{* * *}(.490-.934)$ & & $.696^{\star *}(.500-.967)$ \\
\hline Richer & $.571^{* * *}(.395-.825)$ & & $.599^{\star \star \star}(.409-.878)$ \\
\hline Richest & $.527^{* * *}(.318-.873)$ & & $.585^{* *}(.343-.998)$ \\
\hline Primary & $1.059(.772-1.453)$ & & $1.093(.794-1.503)$ \\
\hline Secondary & $.901(.666-1.217)$ & & $.905(.667-1.227)$ \\
\hline Higher & $.787(.476-1.296)$ & & $.822(.495-1.363)$ \\
\hline \multicolumn{4}{|l|}{ Media Exposure } \\
\hline \multicolumn{4}{|l|}{ No Exposure $®$} \\
\hline Any exposure & $.905(.711-1.151)$ & & $.907(.710-1.158)$ \\
\hline \multicolumn{4}{|l|}{ Household Structure } \\
\hline \multicolumn{4}{|l|}{ Nuclear® } \\
\hline Non-Nuclear & $.940(.775-1.140)$ & & $.967(.796-1.176)$ \\
\hline \multicolumn{4}{|l|}{ Women Work Status } \\
\hline \multicolumn{4}{|l|}{ Not Working ${ }^{\circledR}$} \\
\hline Working & $1.295^{\star *}(1.040-1.613)$ & & $1.261^{* *}(1.010-1.575)$ \\
\hline \multicolumn{4}{|l|}{ Partner Education } \\
\hline \multicolumn{4}{|l|}{ No education $®$} \\
\hline Primary & $.915(.684-1.223)$ & & $.905(.675-1.212)$ \\
\hline Secondary & $1.095(.851-1.409)$ & & $1.112(.860-1.437)$ \\
\hline Higher & $1.258(.820-1.928)$ & & $1.247(.808-1.924)$ \\
\hline \multicolumn{4}{|l|}{ Children ever born } \\
\hline No Child $\circledast$ & & & \\
\hline
\end{tabular}


Citation: Satish Kumar C, Suresh J, Chauhan BG. Burden of Anaemia among Women in Jharkhand, India: Does Lifestyle Behaviour Matters? J Nutri Health. 2015;1(2): 9.

ISSN: 2469-4185

\begin{tabular}{|c|c|c|c|}
\hline 1-2 Child & $1.513^{* * *}(1.107-2.068)$ & & $1.534^{* * *}(1.118-2.103)$ \\
\hline 3-4 Child & $1.550^{* * *}(1.089-2.206)$ & & $1.586^{* * *}(1.111-2.264)$ \\
\hline 5 and above & $1.576^{* *}(1.070-2.323)$ & & $1.621^{* * *}(1.095-2.400)$ \\
\hline \multicolumn{4}{|l|}{ Life style variables } \\
\hline \multicolumn{4}{|l|}{ BMI of Women } \\
\hline \multicolumn{4}{|l|}{ Total thin $(<18.5 \mathrm{~kg} / \mathrm{m} 2){ }^{\circledR}$} \\
\hline Normal(18.5- 24.9 kg/m2) & & $.955(.809-1.127)$ & $1.005(.828-1.220)$ \\
\hline Overweight \& obese $(\geq 25 \mathrm{~kg} / \mathrm{m} 2)$ & & $.629^{* * *}(.442-.896)$ & $.703^{*}(.466-1.061)$ \\
\hline \multicolumn{4}{|l|}{ Smoke/Consume Tobacco } \\
\hline \multicolumn{4}{|l|}{$\mathrm{No} \circledast$} \\
\hline Yes & & $1.353^{* *}(1.023-1.790)$ & $.994(.729-1.354)$ \\
\hline \multicolumn{4}{|l|}{ Consume Fruits } \\
\hline \multicolumn{4}{|l|}{ Never® } \\
\hline Daily & & $.663(.383-1.148)$ & $.687(.357-1.321)$ \\
\hline Weekly & & $.778(.507-1.194)$ & $.795(.489-1.293)$ \\
\hline Occasionally & & $.919(.625-1.353)$ & $.865(.561-1.333)$ \\
\hline \multicolumn{4}{|l|}{ Consumed Milk or Curd } \\
\hline \multicolumn{4}{|l|}{ Never $\circledast$} \\
\hline Daily & & $.620^{\star * *}(.470-.819)$ & $.916(.649-1.293)$ \\
\hline Weekly & & $.474^{\star \star *}(.342-.657)$ & $.620^{\star * \star}(.422-.911)$ \\
\hline Occasionally & & $.621^{* * *}(.509-.758)$ & $.752^{\star * *}(.595-.950)$ \\
\hline \multicolumn{4}{|l|}{ Pluses and beans } \\
\hline \multicolumn{4}{|l|}{ Daily® } \\
\hline Weekly & & $1.189 *(.974-1.452)$ & $.921(.726-1.169)$ \\
\hline Sometime & & $1.257^{*}(.960-1.645)$ & $.976(.709-1.343)$ \\
\hline \multicolumn{4}{|l|}{ Green leafy vegetable } \\
\hline \multicolumn{4}{|l|}{ Daily® } \\
\hline Weekly & & $.882(.733-1.061)$ & $.901(.729-1.114)$ \\
\hline Sometime & & $.940(.708-1.248)$ & $.991(.716-1.370)$ \\
\hline \multicolumn{4}{|l|}{ Eating non-vegetarian } \\
\hline \multicolumn{4}{|l|}{ Never® } \\
\hline Occasionally & & $1.228(.927-1.627)$ & $1.118(.807-1.551)$ \\
\hline Weekly & & $1.004(.702-1.435)$ & $.997(.658-1.512)$ \\
\hline
\end{tabular}

Note: $\circledast$ is the reference category, ${ }^{* * *} p<0.01,{ }^{* *} p<0.05,{ }^{*} p<0.1$

consumption of milk or curd. Women who consumed pulses and beans frequently were significantly less likely to be anaemic than those who either ate weekly and sometime. However, it must be mentioned that frequent consumption of pulses has the strongest influence on reduced risk of anaemia compared with other food items mentioned above (OR=1.189, C l= $0.974,1.452)$ for consumption of weekly consumption of pluses and beans; $\mathrm{OR}=1.257, \mathrm{Cl}=0.960,1.645$ for sometime consumption of pulses and beans. Although, the odds to be anaemic is less among those women who ate green leafy vegetable weekly and sometime compare to those who consumed green leafy vegetable daily. Similarly, women who eating non-vegetarian food occasionally or weekly are more likely to be anaemic than who never ate non-vegetarian $(\mathrm{OR}=1.228, \mathrm{Cl}=0.927-1.627)$ for women who ate non- vegetarian occasionally and $\mathrm{OR}=1.004, \mathrm{Cl}=0.702,1.435$ for women who ate non-vegetarian weekly.

Model 3, adjusted for the all socio-economic demographic and life style factor showing the odds of anaemia among women. From this model, it is observed that rural women are $2 \%$ less likely to be anaemic $(\mathrm{OR}=0.986 \mathrm{Cl}=0.730,1.332)$ than urban women. In all socio-economic and demographic variables the value of odds ratio is slightly increases in the model 3 than model 1 . However in model 3 the life style factor such as women with normal BMI at equal risk of being anaemic $(\mathrm{OR}=1.005, \mathrm{Cl}=0.828,1.220)$ with women with normal BMI. In contrast, overweight or obese women have significantly fewer odds to be anaemic $(\mathrm{OR}=0.703, \mathrm{Cl}=0.466,1.061)$ than total thin women and whose women who smoke or consume tobacco have fewer odds of being anaemic $(\mathrm{OR}=0.994, \mathrm{Cl}=0.729,1.354)$ than women who 
Citation: Satish Kumar C, Suresh J, Chauhan BG. Burden of Anaemia among Women in Jharkhand, India: Does Lifestyle Behaviour Matters? J Nutri Health. 2015;1(2): 9.

ISSN: 2469-4185

consume or smoke tobacco. It is also observed that those women who ate pluses or beans either weekly or sometime have less odds than those women who ate pluses or beans daily $(\mathrm{OR}=0.921 \mathrm{C} \mathrm{l}=.726$, 1.169 for weekly and $\mathrm{OR}=0.976 \mathrm{Cl}=0.709,1.343$ for sometime) which is inversely showing by model 2. Similarly, those women who ate non-vegetarian weekly the odds of being anaemic are less than those women who ate never.

\section{Discussion}

Poor socio-economic development state of Jharkhand is evident in India. The level of development of the state affects weak segment and women population. The study results are clear and loud that women in Jharkhand are at greater risk of being anaemic. The overall anaemia among reproductive age women is higher than the national average. The primary concern of the study was to determine the lifestyle behaviour factors and level of anaemia among the reproductive age women in Jharkhand. The results were showing the significant relationship with lifestyle behaviour with the level of anaemia among the reproductive age women this may have serious health consequences during their pregnancy and childbirth. It was observed that the women who reported smoke or consume tobacco were more likely to be anaemic than those who did not smoke or consume tobacco the similar results were also found in previous studies [11-13].

This study also highlights the facts that the higher prevalence of anaemia among working women is greater than non-working women this may be due to the dual burden of household work and professional responsibility. However, women who consume pulses and beans frequently are less likely to be anaemic than those not. This is clearly indicating the patterns of food consumption have direct relationship with anaemia status of women. It is hypnotised that rural women are at greater risk of being anaemic than urban women. However, if we control other life style factors the in the model it is found that rural women are $2 \%$ less likely to be anaemic than their counterparts and some of the previous studies also reported [4].

Programmes and policies should address the issue of iron fortification through the life-cycle approach so that iron deficiency can be reduced during pregnancy and childbearing. Integrated child development scheme (ICDS) should be deal with pregnant women and children. Providing iron rich food during childhood is important. Promoting nutritional awareness among the married women is another important aspect which can be done through the National Rural Health Mission. The states of Jharkhand have 32\% tribal population of the total population and have different sociocultural differences with other population. Tribes are also live under the extreme poverty and backwardness. Addressing the contextual factors of the tribes related to nutritional habits is required to effective interventions.

\section{Conclusion}

It is clear from the study that lifestyle behaviour has effects on anaemia levels among the women in Jharkhand. Study results illustrated that those women use smokeless tobacco and smokes are at greater risk for being anaemic. The dietary intake patterns and consumption of non-vegetarian food and milk curd are significant predictors for the level of anaemia among the women. The specific interventions are required to address the higher anaemia levels in Jharkhand women. The programmes which are aimed to provide awareness among women need to be accelerated.

\section{References}

1. McLean E, Cogswell M, Egli I, Wojdyla D, de Benoist B (2009) Worldwide prevalence of anaemia, WHO Vitamin and Mineral Nutrition Information System, 1993-2005. Public Health Nutr 12: 444-454.

2. Balarajan $Y$, Ramakrishnan U, Ozaltin E, Shankar AH, Subramanian SV (2011) Anaemia in low-income and middle-income countries. Lancet 378 : 2123-2135

3. Bhutta ZA, Ghishan F, Lindley K, Memon IA, Mittal S, et al. (2004) Persistent and chronic diarrhea and malabsorption: Working Group report of the second World Congress of Pediatric Gastroenterology, Hepatology, and Nutrition. J Pediatr Gastroenterol Nutr 39 Suppl 2: S711-S716.

4. Ghosh S (2009) Exploring socioeconomic vulnerability of anaemia among women in eastern Indian States. J Biosoc Sci 41: 763-787.

5. Ramanakumar AV (2004) Reviewing disease burden among rural Indian women. Online J Health Allied Sci 2: 1.

6. Malhotra P, Kumari S, Kumar R, Varma S (2004) Prevalence of anemia in adult rural population of north India. J Assoc Physicians India 52: 18-20.

7. Sauvaget C, Ramadas K, Thomas G, Vinoda J, Thara S, et al. (2008) Body mass index, weight change and mortality risk in a prospective study in India. Int J Epidemiol 37: 990-1004.

8. Griffiths PL, Bentley ME (2001) The nutrition transition is underway in India. J Nutr 131: 2692-2700

9. Singh RK (2013) Lifestyle behavior affecting prevalence of anemia among women in EAG states, India. J Public Health 21: 279-288.

10. Kedir H, Berhane Y, Worku A (2013) Khat chewing and restrictive dietary behaviors are associated with anemia among pregnant women in high prevalence rural communities in eastern Ethiopia. PLoS One 8: e78601.

11. Tungtrongchitr R, Pongpaew $P$, Soonthornruengyot $M$, Viroonudomphol $D$, Vudhivai N, et al. (2003) Relationship of tobacco smoking with serum vitamin B12, folic acid and haematological indices in healthy adults. Public Health Nutr 6: 675-681.

12. Subramoney S, Gupta PC (2008) Anemia in pregnant women who use smokeless tobacco. Nicotine Tob Res 10: 917-920.

13. Pratinidhi A, Ganganahalli P, Kakade SV (2014) Untoward obstetric outcome among Smokeless Tobacco (ST-Mishri) users in Western Maharashtra. Bangladesh J Med Sci 13: 401-405. 